\title{
INCIDENCE OF NEW ZEALAND FLOWER THRIPS IN STONEFRUIT ORCHARDS BETWEEN FLOWERING AND HARVEST
}

\author{
G.F. McLAREN ${ }^{1}$ and P.A. ALSPACH ${ }^{2}$ \\ ${ }^{1}$ HortResearch, Clyde Research Centre, Alexandra RD1, Central Otago, \\ New Zealand \\ ${ }^{2}$ HortResearch, Nelson Research Centre, P.O. Box 220, Old Mill Road, Motueka \\ Corresponding author:GMcLaren@hortresearch.co.nz
}

\begin{abstract}
New Zealand flower thrips, Thrips obscuratus (Crawford) (NZFT), feeds on the nectar and pollen of stonefruit flowers and was thought to then disappear from orchards for 2-3 months until the fruit ripen. Aerial populations of NZFT were sampled in Central Otago orchards using white sticky traps. Samples were taken in a peach orchard for 6 months from flowering until after harvest and in two cherry orchards for six weeks during harvest. In all three orchards, populations of NZFT reached high numbers in December. In the peach block NZFT numbers peaked in December, several weeks before the fruit began to ripen. It was concluded that NZFT can live in stonefruit orchards, probably feeding on newly emerged leaves of peaches or cherries, or in the vegetation of the irrigated orchard floor. Trapped thrips could also have come from other blocks within the larger orchard areas or from outside sources.
\end{abstract}

Keywords: New Zealand flower thrips, Thrips obscuratus, peaches, cherries, traps, food sources.

\section{INTRODUCTION}

New Zealand flower thrips, Thrips obscuratus (Crawford) (NZFT), is an indigenous polyphagous species that feeds on the nectar and pollen of flowers of stonefruit crops and on ripening fruit during harvest (McLaren 1992; Teulon \& Penman 1994). In Central Otago, the adults are largely responsible for the damage caused to the ovary of nectarine flowers, resulting in scarred fruit at harvest (McLaren 1992; McLaren \& Fraser 2000). Larvae sometimes appear on nectarine trees for about 2 weeks after petal fall but their association with damage to fruit has never been established, largely because they occur in relatively low numbers in Central Otago. Higher numbers of larvae were found on nectarines in Hawke's Bay (Lo \& McLaren 2003) and Canterbury (Teulon \& Penman 1994) but in the case of Hawke's Bay, the larvae may not have been NZFT. In Central Otago, a second generation of adults appears on nectarine trees about 5 weeks after bloom and can cause significant damage to fruitlets if present in high numbers (McLaren 1992; McLaren \& Fraser 2000). Adult NZFT have been observed feeding on peach, nectarine and apricot fruit at harvest time, both in the field and after harvest (McLaren \& Dale 1987; Teulon \& Penman 1990; McLaren et al. 1997). NZFT adults are not found on green fruit, but they feed on ripening fruit with numbers increasing during the last week before harvest. They damage the skin, and may cause the fruit to fail export quarantine standards (G.F. McLaren, unpubl. data).

It has been assumed by most authors (Teulon \& Penman 1996; McLaren \& Fraser 2001) that if there are neither flowers nor fruit available between flowering and harvest, NZFT adults will leave the orchards to find flowering host plants elsewhere, and return only when the fruit begins to ripen. It was also thought that the application of insecticides for the control of leafroller (Tortricidae) larvae in November/December would control thrips 
(McLaren \& Fraser 2000). However, it has never been established that NZFT actually disappears from stonefruit orchards between flowering and harvest, nor has it been established that flowers or fruit are necessary for its survival in an orchard. Since NZFT completes about seven generations per growing season in Central Otago, it is possible for it to move between a variety of host plants in any one season (Teulon \& Penman 1990; McLaren \& Fraser 1998). The aim of the current research was to use traps to determine if NZFT survives in stonefruit orchards between shuck fall and harvest.

\section{Traps}

\section{METHODS}

Traps for adult thrips were constructed from white plastic corflute $\left(190 \times 180 \mathrm{~mm}^{2}\right)$ coated on one side with a sticky glue (HO633.2 ${ }^{\circledR}$ ) applied at the rate of $5.5 \mathrm{~g} /$ trap using a custom-made spray applicator. Traps were attached to fruit tree branches by twist ties that were passed through holes drilled through two corners of the coreflute. The traps were installed approximately $1.7 \mathrm{~m}$ above the ground, with the sticky side facing north or east to ensure maximum light exposure each day.

\section{Orchards and trap placement}

One trial was conducted in a 3.7 ha commercial planting of three cultivars of peaches at the HortResearch Clyde Research Centre. This block was part of a 50 ha planting of stonefruit and pipfruit trees. Other land uses in the vicinity included ornamental plantings, viticulture and pasture. White sticky traps were operated from 1 October 2005 to 24 March 2006. Five traps were set approximately $40 \mathrm{~m}$ apart within the block. The peach trees were at least 5 years old and close-planted, with 1667 peach trees/ha. The block was planted in three white-fleshed late-maturing cultivars, Southern Ice (harvested 8-9 February 2006), Coconut Ice (harvested 15-17 February 2006) and Southern Star (harvested 21-22 February 2006). The following sprays were applied during the trial: 22 November 2005 - mineral oil $1 \%+$ Bacillus thuringiensis $50 \mathrm{~g}$ Delfin $^{\circledR} / 100$ litres; 6 December 2005 - $37.5 \mathrm{~g}$ ai/100 litres chlorpyrifos; 14 February 2006 - pyrethrum $14 \mathrm{~g}$ ai/100 litres.

Two other trials were conducted in commercial cherry orchards, with each block covering approximately 4 ha. Both blocks were part of larger stonefruit orchards, covering at least 50 ha. These orchards were located in the Roxburgh and Cromwell districts, $45 \mathrm{~km}$ to the south and $35 \mathrm{~km}$ to the north of Clyde respectively. Twelve traps were installed within and on the edges of each block of cherries and were run from 16 December 2005 to 25 January 2006. The cherry trees were at least 5 years old and close-planted, with 750-1000 cherry trees/ha at Roxburgh and 1000 cherry trees/ha at Cromwell. Both cherry blocks contained cv. Stella and cv. Sweetheart, plus cv. Bing at Roxburgh and cv. Lapins at Cromwell. While the Cromwell orchard harvested fruit from 20 December 2005 to 10 January 2006, heavy rain damaged the early cherries at Roxburgh and only cv. Sweetheart was harvested from that orchard in mid-January 2006. No insecticides were applied during the trial at Roxburgh, but spinosad had been applied on 30 November 2005, two weeks before the traps were installed. At Cromwell no insecticides were applied from flowering to harvest.

The 2005/06 season was particularly dry with $282 \mathrm{~mm}$ rain falling from 1 March 2005-28 February 2006 (average rainfall for the past 20 years at Clyde Meteorological Station I $59235=429 \mathrm{~mm}$ ). During spring, all blocks were protected from frost using overhead sprinklers (September-November). These sprinklers were then used for weekly irrigation on the peaches at Clyde while under-tree sprinklers were used to apply more frequent irrigation on the cherries at Roxburgh and Cromwell, so that, in the lead-up to harvest, all cherry trees were maintained at very high moisture levels. In all cases the inter-row space was occupied by grasses, clover and broad-leaf weeds which were mown every 2-3 weeks. A 2-3 metre wide strip under the trees was kept weed-free by annual herbicide applications at each site. 


\section{Thrips catches}

Sticky traps were changed every 2 weeks. Numbers of thrips/trap were recorded in the field in one week and the laboratory the next, after the traps had been removed. Identification of doubtful specimens was confirmed in the laboratory, using a $\times 10$ handlens. A small proportion of thrips $(<5 \%$ of the sample) were small and palecoloured. These were not included in the tally as it was impossible to separate specimens of Thrips tabaci from pale T. obscuratus when they were embedded in the sticky glue. Statistics

For the Clyde peach data, there were sufficient trapping occasions to allow an iterative procedure to be used to estimate the daily trap catch (P.A. Alspach, unpubl. data). Briefly, the procedure used the mean catch per trap per day as the initial estimate. A locally weighted regression was fitted to these values to give an estimated functional form. A revised estimated catch per trap per day was then computed using this form as a basis for weighting the average. Iteration continued until the estimates had stabilised. The estimated mean numbers of thrips per trap per day, on the days of trap clearance, were log-transformed and subject to linear mixed effects modelling with date as the fixed effect factor and trap as the random effect. Exploratory plots revealed that even after transformation, the variances at any date tended to be higher when the catch was higher. This within-group variance structure was accommodated using an exponential function of the variance covariate (Pinheiro \& Bates 2000). The cherry data were also log-transformed, after dividing the counts for each trap by the number of days for which it was set. Means and standard errors were computed for each time separately and are presented in a bar chart, along with estimates from the peach data, for comparison. The programme R 2.2.1 (R Development Core Team 2005) was used for all statistical analyses.

\section{RESULTS}

Numbers of NZFT trapped per day in the peaches increased steadily from late October, reaching a peak towards the end of December 2005 (Fig. 1). Numbers began to decline in January. This decrease in numbers became more rapid after harvest. The decline in numbers of adult NZFT during January and early February 2006 was confirmed by results from a different trap array (G.F. McLaren, unpubl. data). The greatest increase in numbers occurred very soon after the application of chlorpyrifos on 6 December 2005.

In the two cherry blocks, the levels of NZFT catches were similar between orchards and between weeks ( $P>0.05$ ), apart from the Roxburgh site where numbers were higher in late December to early January than in early December or late January $(\mathrm{P}<0.05)$ (Fig. 2). Daily trap catches were remarkably similar between the three orchards, despite the considerable distances between them, especially the $80 \mathrm{~km}$ between the Cromwell and Roxburgh sites, and differences in harvest dates. Numbers of NZFT trapped were similar inside or on the edge of each cherry block $(\mathrm{P}>0.05)$. 


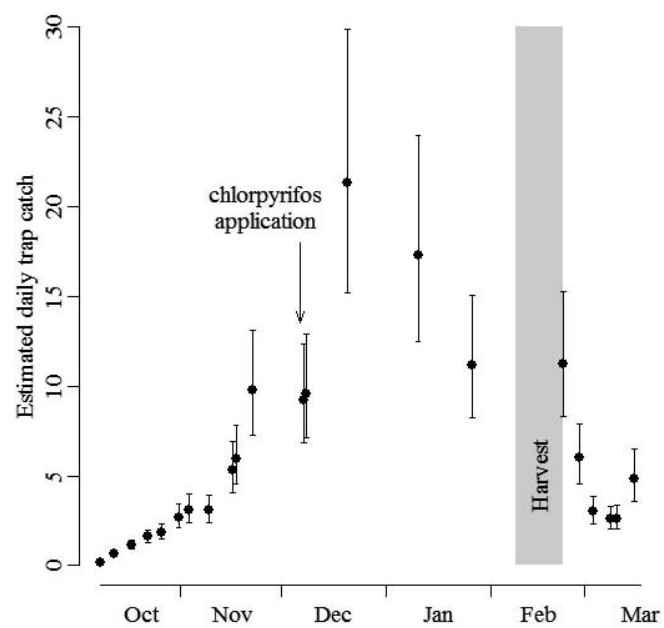

FIGURE 1: Estimated mean daily catch of NZFT per trap on peaches at Clyde over the 2005-06 growing season. Vertical bars show one standard error each way at each time when the traps were counted. The harvest period is marked in grey, and the chlorpyrifos application is indicated by an arrow.

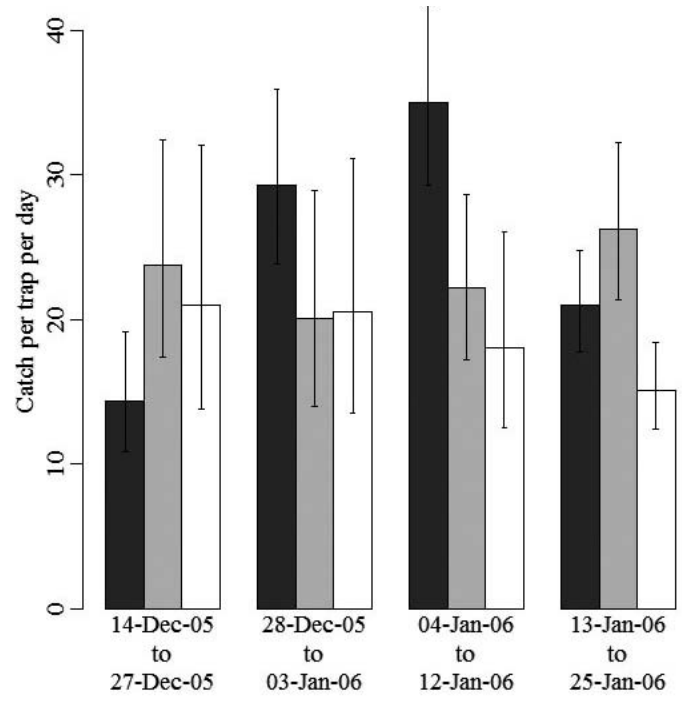

FIGURE 2: Average catch per trap per day of thrips at four separate times for the cherries at Roxburgh (black bars) and Cromwell (grey bars), and peaches at Clyde (white bars). Vertical bars show one standard error each way. There were 12 traps at each time for each cherry orchard but only five for the peaches. Peach averages were computed from the interpolated daily trap catch estimates and the standard errors do not include the error associated with interpolation. 


\section{DISCUSSION}

Teulon \& Penman (1996) found that NZFT numbers peaked in peach blocks in December in Canterbury and these peaks coincided with the beginning of fruit ripening in both years of their study. They concluded that most NZFT adults found in orchards "appeared to have originated from elsewhere" rather than from within the orchard. The time of highest NZFT trap catches in the peach block in the current study was also December, but this timing did not coincide with the ripening of the late-maturing cultivars in the block. This raised doubts that all NZFT adults found on fruit had flown into the orchard to find ripening fruit. The results presented here suggest that NZFT can survive and increase within the orchard between shuck fall and harvest and complete several generations there. NZFT larvae have frequently been observed on the leaves of peaches in the past (G.F. McLaren, unpubl. data) and cherry leaves have been used as a medium for rearing NZFT (McLaren \& Fraser 1998). It has also been established that NZFT completes at least one generation on leaves of nectarine in the spring (McLaren \& Fraser 2000). Therefore, it seems that NZFT does not necessarily disperse from stonefruit orchards between flowering and harvest but can survive on growing tips and leaves, especially in irrigated orchards, where pupae can complete their development. Adult NZFT generally avoid sites with low humidity and full sunlight (McLaren \& Fraser 2003), and will seek sheltered, shady sites such as those offered by new leaves on growing tips. Peach trees set terminal shoot buds and cease to produce fresh leaves once fruit ripening has begun. Therefore, the decline in thrips catches in February/March may be associated as much with the absence of new vegetative growth as the absence of fruit.

Traps reflect the numbers of flying adults in the area, not necessarily the breeding populations on the tree. NZFT populations are known to be extremely mobile, shifting position both within and between trees through the day, probably to maximise their temperature and (high) relative humidity requirements (McLaren \& Fraser 2003). Thus adult thrips caught within a tree may be resident, or have arrived by migration or dispersal, but the size of the orchard plantings in which these trials were run ( $>50 \mathrm{ha}$ ) would suggest that orchard trees are likely to be the most significant source.

Although chlorpyrifos is known as a highly effective protectant against NZFT on nectarines in spring (McLaren \& Fraser 2001), the increase in trap catches within days of the application of chlorpyrifos demonstrated that insecticides applied for leafrollercontrol do not necessarily reduce thrips populations. In the absence of any suggestion of the development of insecticide resistance by NZFT, this result suggests that thrips are constantly moving, and may arrive from surrounding orchard trees and possibly adults emerging from pupae in the orchard floor.

All of the orchards in this study were maintained in a well-irrigated state. This contrasts with the orchards of Teulon \& Penman (1996) that had severe water deficits over the growing season. Irrigation would allow the production of new peach foliage in which NZFT can breed and pupae survive on the ground. McLaren \& Fraser (1998) estimated that NZFT would have completed seven generations in the 1997/98 season. Therefore, over the period of the current study, several generations were possible within the orchard.

There is other evidence that NZFT can survive on vegetative parts of the plant. Martin \& Mound (2004) found NZFT larvae and adults feeding on expanding buds of Pittosporum tenuifolium. It is therefore concluded that NZFT is not restricted in its food supply to pollen, nectar or fruit juice, and hence the assumption that NZFT populations in stonefruit orchards are ephemeral is incorrect. Modern stonefruit orchards, that are both irrigated and closely-planted, probably provide an excellent habitat for NZFT and have become a substitute for its original habitat of native bush and scrublands. It is recognised that NZFT has a very wide host range, so stonefruit orchards will not be the sole source of thrips to infest ripening fruit at harvest time, but they are likely to be a significant contributor. The possibility that orchards are a permanent habitat for NZFT has major implications for methods of controlling them. For example, managed biological control of NZFT, which has not previously been considered, may be a valuable control strategy. 


\section{ACKNOWLEDGEMENTS}

This research was partly funded by the Foundation for Research, Science and Technology (CO6X0301) and partly by Summerfruit New Zealand (cherries only).

\section{REFERENCES}

Lo PL, McLaren GF 2003. Comparison of two methods for sampling thrips on nectarines in spring. New Zealand Plant Protection 56: 151-156.

Martin NA, Mound LA 2004. Host plants for some New Zealand thrips (Thysanoptera: Terebrantia). New Zealand Entomologist 27: 119-123.

McLaren GF 1992. Thrips on nectarines in the spring. Proceedings of the 45th New Zealand Plant Protection Conference: 111-115.

McLaren GF, Dale JR 1987. Control of thrips on stonefruit at harvest time. DSIR Entomology Division Report Series 8. 40 pp.

McLaren GF, Fraser JA, McDonald RM 1997. The feasibility of hot water disinfestation of summerfruit. Proceedings of the 50th New Zealand Plant Protection Conference: 425-430.

McLaren GF, Fraser JA 1998. Upper thermotolerance of New Zealand flower thrips Thrips obscuratus (Crawford). Proceedings of the 51st New Zealand Plant Protection Conference: 204-210.

McLaren GF, Fraser JA 2000. Development of thresholds for insecticidal control of New Zealand flower thrips on nectarines in spring. New Zealand Plant Protection 53: 194-199.

McLaren GF, Fraser JA 2001. Alternative strategies to control New Zealand flower thrips on nectarines. New Zealand Plant Protection 54: 10-14.

McLaren GF, Fraser JA 2003. Diurnal activity of New Zealand flower thrips on stonefruit in spring and at harvest. Marullo R, Mound L ed. Proceedings of the 7th International Symposium on Thysanoptera. Pp. 269-271.

Pinheiro JC, Bates DM 2000. Chapter 5. Mixed-Effects Models in S and S-PLUS. Springer-Verlag, New York. 528 pp.

R Development Core Team 2005. R: A language and environment for statistical computing. R Foundation for Statistical Computing, Vienna, Austria. http://www. R-project.org (accessed March 2006).

Teulon DAJ, Penman DR 1990. Host records for the New Zealand flower thrips (Thrips obscuratus (Crawford) Thysanoptera: Thripidae). New Zealand Entomologist 13: 46-51.

Teulon DAJ, Penman DR 1994. Phenology of New Zealand flower thrips, Thrips obscuratus (Crawford) (Thysanoptera: Thripidae), on nectarine and peach flowers. New Zealand Entomologist 17: 70-77.

Teulon DAJ, Penman DR 1996. Thrips (Thysanoptera) seasonal flight activity and infestation of ripe stonefruit in Canterbury, New Zealand. Journal of Economic Entomology 89(3): 722-734. 